\title{
Interactions among ENSO, the Monsoon, and Diurnal Cycle in Rainfall Variability over Java, Indonesia
}

\author{
JiAN-HuA QIAN AND ANDREW W. ROBERTSON \\ International Research Institute for Climate and Society, Columbia University, Palisades, New York \\ VINCENT MORON \\ CEREGE, UMR 6635 CNRS, Aix-Marselle University, Aix en Provence, and Institut Universitaire \\ de France, Paris, France
}

(Manuscript received 8 October 2009, in final form 9 June 2010)

\begin{abstract}
Using a high-resolution regional climate model-the Abdus Salam International Centre for Theoretical Physics Regional Climate Model version 3 (RegCM3) - and station and satellite observations, the authors have studied the spatial heterogeneity of climate variability over Java Island, Indonesia. Besides the wellknown anomalous dry conditions that characterize the dry and transition seasons during an El Niño year, analysis of regional model output reveals a wet mountainous south versus dry northern plains in precipitation anomalies associated with El Niño over Java during the peak rainy season. Modeling experiments indicate that this mountains/plains contrast is caused by the interaction of the El Niño-induced monsoonal wind anomalies and the island/mountain-induced local diurnal cycle of winds and precipitation. During the wet season of El Niño years, anomalous southeasterly winds over the Indonesian region oppose the climatological northwesterly monsoon, thus reducing the strength of the monsoon winds over Java. This weakening is found to amplify the local diurnal cycle of land-sea breezes and mountain-valley winds, producing more rainfall over the mountains, which are located closer to the southern coast than to the northern coast. Therefore, the variability of the diurnal cycle associated with this local spatial asymmetry of topography is the underlying cause for the heterogeneous pattern of wet south/dry north rainfall anomalies during El Niño years. It is further shown that the mean southeasterly wind anomalies during December-February of El Niño years result from more frequent occurrence of a quiescent monsoon weather type, during which the strengthened sea-breeze and valley-breeze convergence leads to above normal rainfall over the mountains.
\end{abstract}

\section{Introduction}

Climate variability and change signals are heterogeneous at various spatial scales, especially over regions of complex topography; therefore, their uncertainty (predictability) is thought to be larger (smaller) at smaller spatial scales. However, climate-related social and economic applications often require local information on climate variability and predictability in great geographical detail. On the one hand, climate variability in any local region is connected to the global environment through advection, wave propagation, and teleconnections; thus, regional climate prediction has to be considered in a global

Corresponding author address: Jian-Hua Qian, IRI, Lamont Campus, Columbia University, 61 Route 9W, Palisades, NY 10964. E-mail: jqian@iri.columbia.edu context. On the other hand, although climate teleconnections are of global scale, local modulations-forced, for example, by finescale topography of terrain or landsea contrasts-may play an important role. Therefore, understanding the role of multiscale interaction in regional climate is critical for climate prediction and change studies and applications in weather- and climate-related risk management.

Java Island is the most populated island and most important industrial and agricultural region in Indonesia. It is located in the deep tropics of the Southern Hemisphere, at the center of the Asian-Australian monsoon region (Ramage 1968). It is zonally elongated and slightly tilted in the northwest-southeast direction, with a central mountain range that runs the length of the island. Figure 1a shows the terrain heights based on United States Geological Survey (USGS) 2-min high-resolution elevation 
(a) USGS $2-$ min resolution elevation

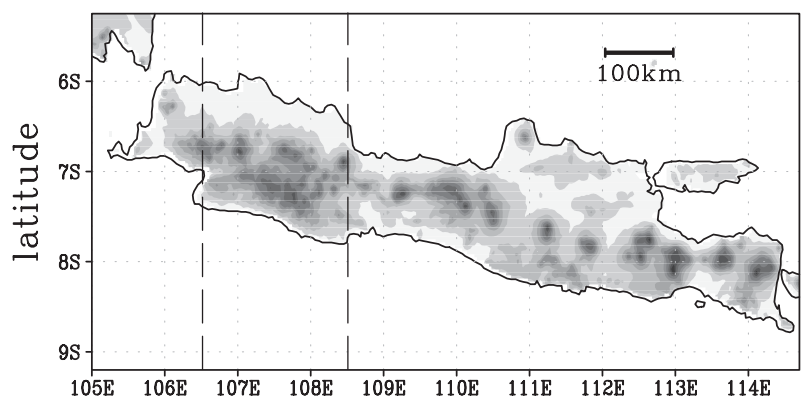

(b) RegCM3 $25 \mathrm{~km}$-grid terrain height

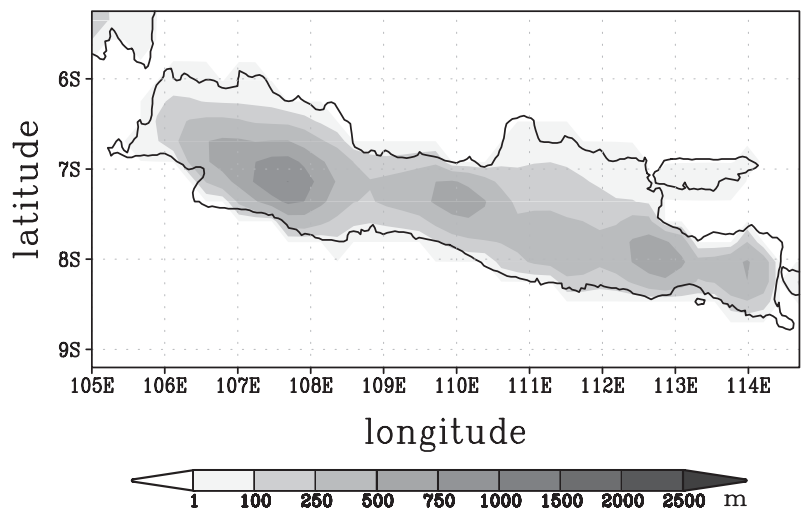

FIG. 1. Terrain heights ( $\mathrm{m}$ ) over Java Indonesia in (a) the USGS observation and (b) RegCM3 modeled terrain with $25-\mathrm{km}$ grids. The two vertical dashed lines denote the longitudes of $106.5^{\circ}$ and $108.5^{\circ} \mathrm{E}$. The meridional belt is used for cross-sectional analyses in Figs. 4 and 6.

data. The central mountain range is composed of a series of quasi-circular small volcanoes, except over western Java where the mountains are more continuously connected. In general, the central mountain range is closer to the southern coast than to the northern coast, except over central Java. Monsoonal winds and the regions of maximum rainfall associated with the intertropical convergence zone (ITCZ) migrate across Java annually, giving rise to a distinct wet season during boreal winter and a dry season during boreal summer, with transitional seasons between.

At the planetary scale, the Asian monsoon is driven by differential heating caused by the annual march of the sun and the spatial asymmetries of the Eurasian continent, the Pacific and Indian Oceans, and Australia ( $\mathrm{Li}$ and Yanai 1996; Hung et al. 2004; Chang et al. 2005). At local scale of Java Island, rainfall is complicated by the underlying lower boundary forcing by highly complex island topography and land-sea contrasts (Qian 2008). For example, wind-terrain interactions produce more rainfall on the windward side of mountains (Chang et al. 2005), leading to strong modulation of rainfall patterns as the direction of the winds reverses seasonally. The
Indonesian Bureau of Meteorology, Climatology, and Geophysics (BMKG) classified 293 areas of different rainfall characteristics across Indonesia, reflecting enormous complexity and heterogeneity.

Indonesian climate is strongly affected by the interannual variation of the tropical sea surface temperature (SST) in the Pacific and Indian Oceans associated with El Niño-Southern Oscillation (ENSO) and the Walker circulation (Bjerknes 1969; Zebiak 1982; Cane and Zebiak 1985; Ropelewski and Halpert 1987; Aldrian and Susanto 2003). It is well known that dry anomalies prevail during El Niño (i.e., warm ENSO) years over the monsoonal region in Indonesia (Aldrian and Susanto 2003). However, the ENSO impact is more spatially coherent during transitional seasons than during the wet season (Haylock and McBride 2001), and this large spatial coherence in rainfall anomalies averaged over the September-November (SON) transition season has been traced to the large spatial coherence of anomalies in monsoon onset date (Moron et al. 2009). During El Niño years, the location of maximum rainfall in the Pacific basin shifts from the equatorial western Pacific toward the central eastern Pacific, following the eastward displacement of warm SST anomalies (Hendon 2003; McBride et al. 2003; Juneng and Tangang 2005). Consequently, the rising branch of the Walker circulation that corresponds to the maximum rainy region shifts eastward over the warm waters, and the anomalous descending region becomes located slightly east of Indonesia (Bjerknes 1969; Wang et al. 2000; Hendon 2003); thus, the low-level wind anomalies over Indonesia are easterly, in the same direction as the mean monsoonal winds during SON (southeasterlies), but become opposite to the mean monsoonal winds during December-February (DJF) (northwesterlies) (Klein et al. 1999; Hamada et al. 2002; Giannini et al. 2007). Therefore, the El Niño increases the monsoonal wind speed during SON, but weakens the monsoonal winds during DJF in Indonesia (Bjerknes 1969; McBride et al. 2003; Juneng and Tangang 2005). Hendon (2003) proposed that the weakening of the relationship between ENSO and Indonesian rainfall from austral winter to summer is linked to this differential impact on monsoon wind speed, acting to increase evaporation and cool SSTs, suppressing rainfall during SON, while decreasing evaporative cooling during DJF.

At smaller scales, analysis of station data by Giannini et al. (2007) revealed dipolar rainfall anomalies over Java during the January-June half-year following the peak El Niño events. Moron et al. (2010, hereafter MRQ) found similar spatial structures in high-resolution regional climate model (RCM) simulations and identified associations with changes in the strength of the diurnal cycle. It was hypothesized that weak-wind weather types 
associated with El Niño during the peak of the rainy season cause an anomalous amplification of the diurnal cycle, resulting in positive rainfall anomalies at the seasonal scale.

The objective of the present paper is to analyze this hypothesis in detail using further analyses as well as additional RCM simulations in which the role of orography is removed. New evidence is presented to clearly demonstrate that interactions between ENSO and the seasonal cycle of large-scale monsoonal winds, together with the impact of the latter on the amplitude of the diurnal cycle of rainfall, are key to understanding spatial patterns of seasonal rainfall anomalies over Java and their temporal evolution between the transition and peak rainfall season. The paper is organized as follows: section 2 details the observed and simulated data used for the analysis. Section 3 describes the background of monsoon and ENSO impacts over the broad region of Indonesia. Section 4 analyzes the finescale spatial pattern of anomalous rainfall over Java during ENSO years as revealed in the regional model results and rain gauge data and examines the underlying multiscale physical processes in terms of the diurnal cycle using the modeling results and observations. The connections to intraseasonal variability are documented in section 5 using a weather-typing analysis. Section 6 provides further discussions on the multiscale physical processes and their role on the spatial and temporal rainfall variability. Conclusions are presented in section 7 .

\section{Observed and simulated data}

A set of regional model simulations (1979-2000) were made over Indonesia with a $25-\mathrm{km}$ grid resolution to resolve the forcing by local mountains and coastlines, using the Abdus Salam International Centre for Theoretical Physics (ICTP) Regional Climate Model version 3 (RegCM3) (Giorgi et al. 2006; Pal et al. 2007). Its dynamical core is close to that of the hydrostatic version of the fifth-generation Pennsylvania State University (PSU)-National Center for Atmospheric Research (NCAR) Mesoscale Model (MM5), a gridpoint mesoscale model based on the primitive atmospheric equations. The vertical resolution is based on a pressure-based terrain-following sigma coordinate. There are 18 vertical levels, with 6 levels in the lower atmosphere below $1.5-\mathrm{km}$ height. The model was driven with observed SST within the model domain $\left(12^{\circ} \mathrm{S}-8^{\circ} \mathrm{N}, 95^{\circ}-130^{\circ} \mathrm{E}\right)$, and atmospheric data taken from the National Centers for Environmental Prediction (NCEP)-NCAR reanalysis (Kalnay et al. 1996) at the lateral boundaries are used to drive the RegCM3. The terrain of the 25-km-grid RegCM3 is shown in Fig. 1 b. The model roughly resolves the central mountain range along the narrow island, but individual peaks are still not well represented as compared to Fig. 1a. Note the spatial asymmetry with the mountains generally closer to the southern coast than to the northern coast, especially over western Java (such as the belt between the two dashed lines in Fig. 1a, which will be used to derive the northsouth cross section later in Figs. 4 and 6) and eastern Java. Over central Java, the mountains are located roughly in the middle of the island.

Satellite estimates of precipitation data cover both land and ocean, which is important for analyzing rainfall pattern across the coastlines of Java. We used a satelliteestimated rainfall dataset with a quarter-degree resolution, that is, the Climate Prediction Center (CPC) morphing technique (CMORPH; Janowiak et al. 2005). The 3-hourly high-frequency CMORPH data can also be used to study the diurnal cycle of rainfall associated with land-sea breezes and mountain-valley winds (Qian 2008). The CMORPH data are available only recently (after 7 December 2002) and therefore cannot be used for the ENSO composite analysis directly because there are not enough ENSO events after 2002 for a statistically meaningful composite calculation. Monthly CPC Merged Analysis of Precipitation $(\mathrm{CMAP})$ data $\left(2.5^{\circ} \times 2.5^{\circ}\right.$ grid data starting in 1979; Xie and Arkin 1996) and low-level winds (monthly and daily) from the NCEP-NCAR Reanalysis Project (NNRP) were also used in the analysis, together with monthly station precipitation data over Java obtained from the Global Historic Climatology Network (GHCN). Because of missing data before 1921 and after 1976, as well as sparse station coverage before 1950 , we only used the GHCN data during the period 1950-75.

\section{Large-scale impacts of the monsoon and EI Niño on the climate over Java}

To address the role of multiscale processes, we first focus on large-scale processes, which are the Pacific basin-scale phenomena of ENSO and the monsoon over Southeast Asia, with spatial extents on the order of $1000 \mathrm{~km}$ or larger. In contrast, local-scale phenomena of land-sea and mountain-valley breezes over Java Island $(\sim 100 \mathrm{~km})$ will be discussed in section 4 .

Figure 2 shows the 3-month climatology of CMAP precipitation and NNRP low-level winds during the transition (SON) and rainy (DJF) seasons, together with their composite anomalies typical of El Niño years. The El Niño years used in the composite are the strongest six warm ENSO years during the period 1979-2000 with a maximum 3-month SST anomaly in the Niño-3.4 region $\left(5^{\circ} \mathrm{S}-5^{\circ} \mathrm{N}, 120^{\circ}-170^{\circ} \mathrm{W}\right)$ larger than $1^{\circ} \mathrm{C}(1982 / 83,86 / 87$, 87/88, 91/92, 94/95, and 97/98). The low-level NNRP 

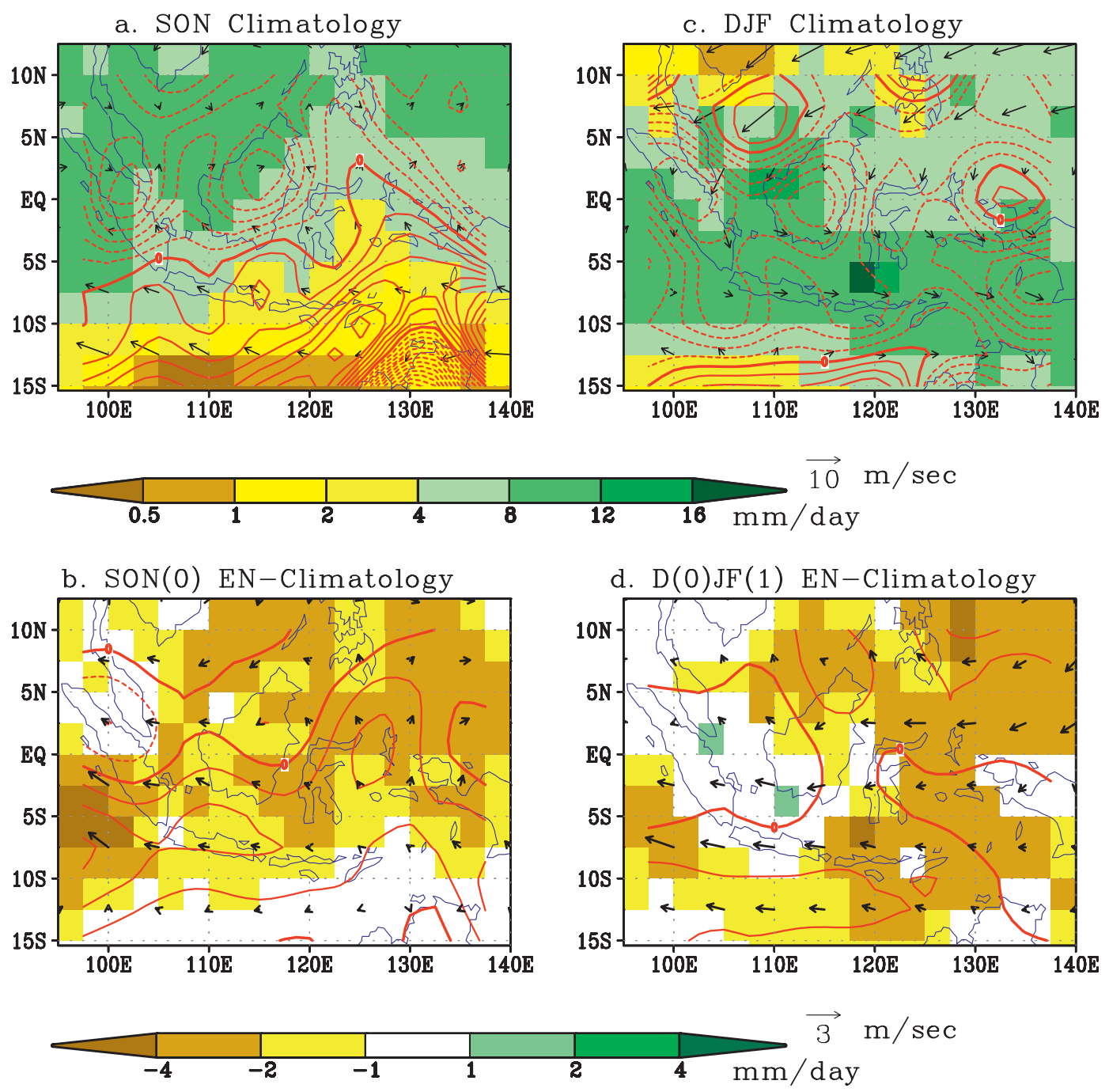

FIG. 2. Climatology (1979-2000) and El Niño minus climatology composites of CMAP precipitation (mm day ${ }^{-1}$, shaded), and NNRP winds ( $\mathrm{m} \mathrm{s}^{-1}$, vectors) and divergence (red contours with interval of $0.5 \times 10^{-6} \mathrm{~s}^{-1}$; divergence is shown with thin solid lines and convergence with thin dashed lines; zero curves are thick solid) at $925 \mathrm{hPa}$, for (a),(b) SON and (c),(d) DJF. El Niño years used for the composite are 1982/83, 86/87, 87/88, 91/92, 94/95, and 97/98. El Niño developing years are denoted by $(0)$.

wind divergence is depicted by the contour lines in Fig. 2.

The annual monsoon rainfall migration in the AsianAustralian region is driven by large-scale differential heating that is affected by two major factors: the incident solar radiation with the seasonal north-south march of the sun and the planetary-scale west-east land-sea contrast of the Eurasian continent and the Pacific Ocean (with their different heat capacities). As a result, the area of maximum rainfall moves annually back and forth in the northwest-southeast direction; it is located near the southern and eastern periphery of the Tibetan Plateau during boreal summer, moves southeastward during boreal fall, reaches Indonesia and Australia during boreal winter, and then moves back northwestward during boreal spring. Because of the larger thermal inertia of the ocean compared to land, the seasonal transition from boreal summer to winter lags the change of the position of the sun by a month or two. Therefore, the average winds during SON are still in the same direction as the boreal summer monsoon of easterlies over Java. The maximum rainfall area extends across northern Sumatra to northwestern Borneo, corresponding to the ITCZ there as shown by the dashed contours in Fig. 2a. Large-scale lowlevel divergence prevails over Java during SON (solid contours), indicating stable atmospheric conditions of descending motion that suppress precipitation. During DJF, in contrast, the ITCZ is situated over Java with a 
maximum low-level convergence of about $-2 \times 10^{-6} \mathrm{~s}^{-1}$, indicating large-scale unstable atmospheric conditions of ascent favoring convection and rain. The northeasterlies of boreal winter monsoon blow from the South China Sea, turn toward the east over Sumatra, and become westerlies over Java.

To examine the impact of ENSO, in Figs. $2 b$ and $2 d$ we show the observed anomaly fields of CMAP precipitation, reanalysis low-level winds, and horizontal divergence of the composite of El Niño years for SON and DJF, respectively. During SON of El Niño developing years (year 0 ), highly spatially coherent negative precipitation anomalies prevail over the Maritime Continent. The anomalous low-level wind speed is small, but the anomalous horizontal divergence is quite large, being about $1 \times 10^{-6} \mathrm{~s}^{-1}$, almost of the same magnitude as its climatological mean in Fig. 2a. Therefore, large-scale atmospheric subsidence over Java is considerably amplified during El Niño years compared to normal years. During DJF, the easterly wind anomalies strengthen, but the magnitude of anomalous divergence decreases to only about $0.5 \times 10^{-6} \mathrm{~s}^{-1}$, rather small compared to its mean value in Fig. 2c. The precipitation anomaly remains mostly negative during this season, but with some small pockets of positive rainfall anomaly. Because of the coarse resolution of CMAP and NNRP data $\left(2.5^{\circ} \times 2.5^{\circ}\right)$, the dimensions of small islands, such as the width of Java (about $2^{\circ}$ or less), are of subgrid scale. The coarseresolution datasets may miss local-scale details, which may be of critical concern for local users of climate risk management. In the next section, we use a high-resolution regional climate model and rain gauge and satellite observations to study this problem.

\section{Local-scale impacts of ENSO}

\section{a. A mountains/plains contrast of rainfall anomalies over Java}

Figure 3 shows the RegCM3 simulated climatology of precipitation and low-level winds during SON (Fig. 3a) and DJF (Fig. 3b). The composites of the simulated anomalies during El Niño years during the two seasons are shown in Figs. 3c and 3d, respectively. Rainfall increases substantially from the premonsoon transition season (SON) to the wet season (DJF). Higher rainfall is simulated over Java Island than over the surrounding seas. Qian (2008) found that this concentration of rainfall over the island is caused by the sea-breeze convergence toward the island and the valley-breeze convergence toward the mountain peaks and is further amplified by the cumulus-merger process, which manifests more during wet seasons than during dry and transition seasons.
Therefore, the diurnal cycle of winds is very important in modulating the local precipitation in this tropical region, and we will study this problem by analyzing the regional model simulations and observations.

The simulated composite rainfall anomalies during El Niño years (averaged values during El Niño years minus the 22-yr climatology) during SON (Fig. 3c) are negative over the whole Java Island. But the rainfall anomalies during the DJF season (Fig. 3d) show a contrast between the northern and southern coast over western and eastern Java, with dry anomalies over the northern coast and wet anomalies over the mountains near the southern coast, forming a north-south dipole pattern over western and eastern Java. Over central Java, however, the positive anomalous rainfall is located toward the middle of the island, close to the mountain peak there. Thus, the positive rainfall anomalies during DJF of El Niño years tend to occur over the mountainous regions of Java.

The simulated wind anomalies are smaller during SON than during DJF (Figs. 3c and 3d), similar to those of the reanalysis data shown in Figs. $2 b$ and $2 d$. During El Niño years, the wind anomalies are roughly in the same direction of the climatological mean monsoonal winds of southeasterlies during SON (thus acting to slightly increase the mean southeasterly wind speed during the transition season) but opposite to the climatological northwesterly winds during DJF (thus reducing the mean northwesterly wind speed during the wet season by the cancelling effect of the southeasterly wind anomalies; Figs. 2c,d and 3b,d). The Student's $t$ test indicates that these wind anomalies are statistically significant above the $90 \%$ level. Previous studies also showed that these ENSO-related seasonally evolving wind differences are statistically significant [e.g., see Fig. 4 in Wang et al. (2000), Fig. 5 in Hendon (2003), and Fig. 5 in Giannini et al. (2007)]. As we will see later, this differential impact on monsoonal wind speed has a profound impact on the intensity of the diurnal cycle of land-sea breezes and mountain-valley winds.

Similar "dipolar" patterns of ENSO-related rainfall variability over Java have previously been found in station observations by Giannini et al. (2007), and a similar composite analysis of GHCN rain gauge data is presented in Figs. $3 \mathrm{e}$ and $3 \mathrm{f}$ for comparison with the model simulations. The period 1950-75 was chosen based on consideration of station data coverage, with the El Niño years (1957/58,63/64, 65/66, 68/69, 69/70, and 72/73) used to calculate the composite anomalies. Consistent with the model simulations, the anomalous precipitation during SON of the El Niño-year composite is negative at every station, whereas the DJF station anomalies exhibit a similar dipolar structure to the RegCM3 simulated 
(a) SON RCM Clim

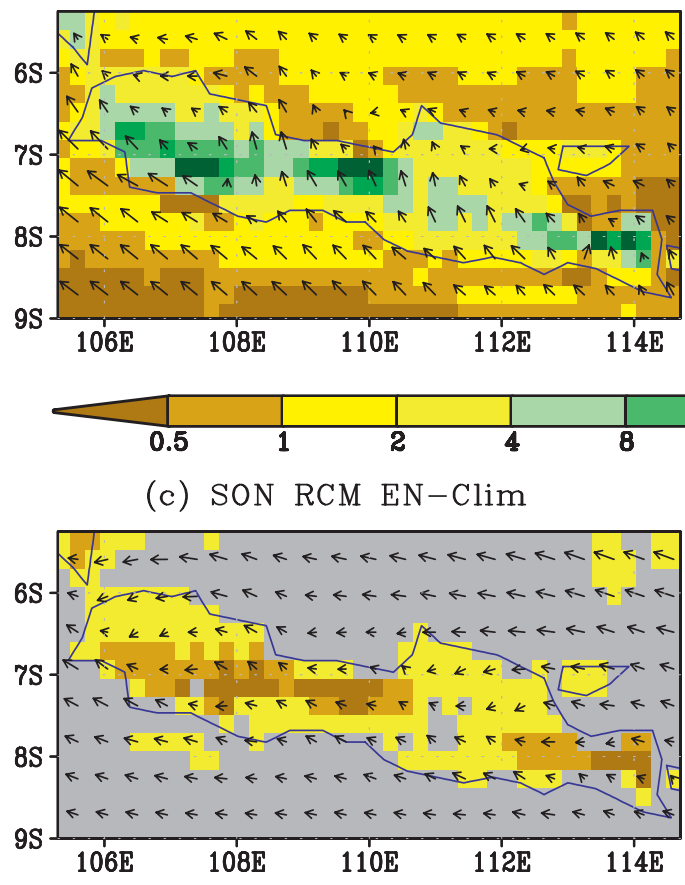

(e) SON GHCN EN-Clim

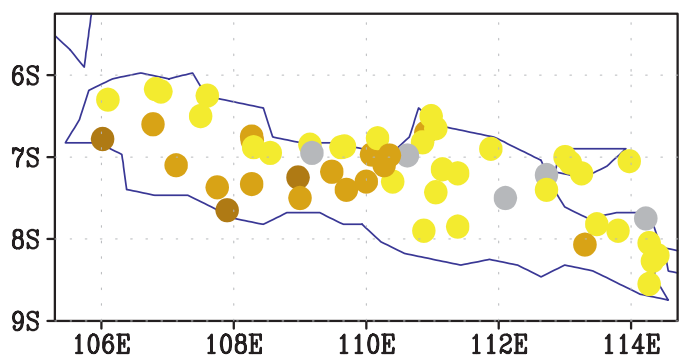

(b) DJF RCM Clim

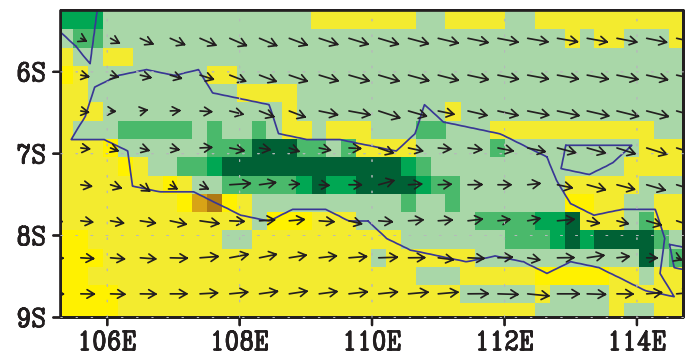

$\frac{1}{12} \quad 16 \mathrm{~mm} /$ day $\overrightarrow{10} \mathrm{~m} / \mathrm{s}$

(d) DJF RCM EN-Clim

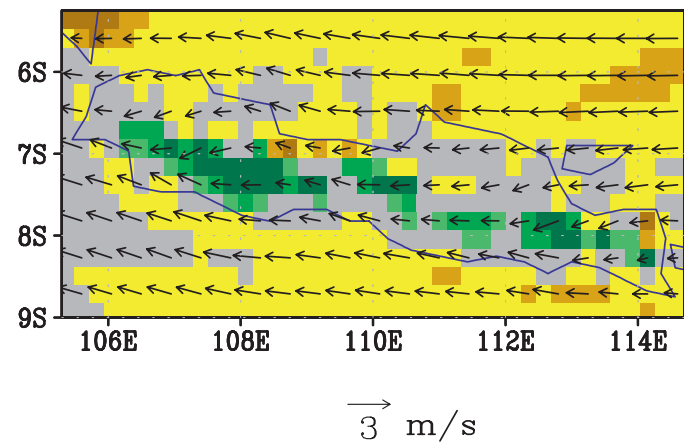

(f) DJF GHCN EN-Clim

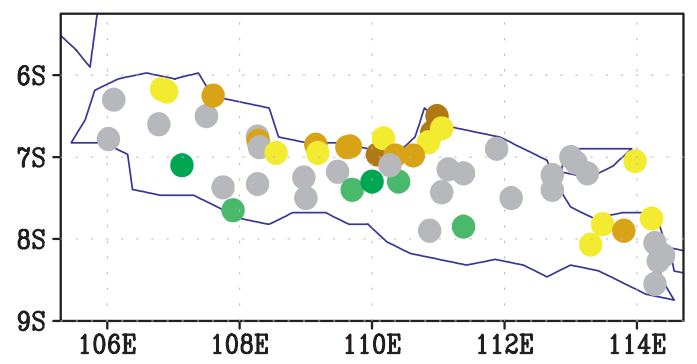

(for $c, d, e, f)$

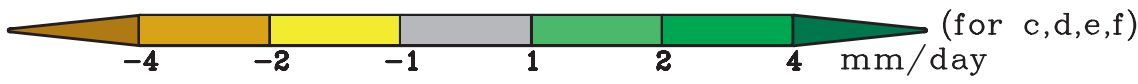

FIG. 3. (a),(b) Climatology of the NCEP-NCAR reanalysis driving RegCM3 simulated rainfall (mm day ${ }^{-1}$ ) during (a) SON and (b) DJF over Java, Indonesia. (c),(d) Composite analysis of El Niño minus climatology of the RegCM3 results of anomalous precipitation ( $\mathrm{mm} \mathrm{day}^{-1}$, shaded) and low-level winds ( $\mathrm{m} \mathrm{s}^{-1}$, vectors) at $\sigma=0.995$ during (c) SON and (d) DJF. El Niño years used for the composite analysis during this time period are 1982/83, 86/87, 87/88, 91/92, 94/95, and 97/98. (e),(f) Composite station rainfall anomalies during El Niño years based on the GHCN dataset for (e) SON and (f) DJF. GHCN data during 1950-75 are used. The El Niño years used for the composite analysis are 1957/58, 63/64, 65/66, 68/69, 69/70, and 72/73.

results over western and eastern Java (Fig. 3d), with negative and positive anomalies at northern and southern stations, respectively. Again consistent with the model, there are positive rainfall anomalies over the middle of central Java, near the mountains there. In contrast, the La Niña-year composites of rainfall anomalies over Java in the GHCN rain gauge data (the average of 1950/51,
$54 / 55,55 / 56$, and 70/71) and in RegCM3 simulated rainfall (average of 1984/85, 88/89, 98/99, and 99/2000) have a similar dipolar pattern to that of El Niño years (but with reversed signs): negative rainfall anomalies over mountains versus positive rainfall anomalies over plains (not shown). The rainfall anomalies during the JanuaryMarch season have also been checked and found to have 
a dipolar pattern similar to that during DJF. In summary, the qualitative agreement during both seasons between observed and simulated ENSO rainfall anomalies is remarkably good in their similarity of spatial patterns.

Recently, Erasmi et al. (2009) reported that the satellite estimated normalized difference of vegetation index (NDVI) in the northern coastal plain of Java is more sensitive to the Southern Oscillation index (SOI), but in the southern part of Java the NDVI is less sensitive to SOI because of moist conditions over the mountains (see their Figs. 7 and 8), indicating the potential influence on vegetation of the dipolar pattern of rainfall anomalies over Java.

\section{b. Analysis of the diurnal cycle and the role of topography}

By analyzing observations and regional modeling results, Qian (2008) showed the important role of the topography of island and mountains and the associated diurnal cycles of land-sea breezes and mountain-valley winds in the spatial distribution of rainfall over Java. To illustrate the impact of topography on the climatological average rainfall distribution, Fig. 4 shows the northsouth cross section of rainfall during DJF over western Java (along the meridional belt of $106.5^{\circ}-108.5^{\circ} \mathrm{E}$ ) in the control run (with mountains) and in a flat-island run (in which a constant terrain height of $1.5 \mathrm{~m}$ is used over the whole Java Island). Black bars at the bottom of Fig. 4 illustrate the simulated mountain heights in the control run over western Java (on the $25-\mathrm{km}$ grid). In the control run, more rainfall falls over the mountain peaks than over the northern slopes and coastal plains. This is caused by the valley-breeze convergence toward the mountain peaks, added onto the background of the island-scale seabreeze convergence during the daytime (Qian 2008). In the flat-island run, however, the rainfall is quite evenly distributed across Java from the south to the north, even with slightly more rainfall near the northern coast.

Figure 5 shows the 3-hourly time bin of anomalous diurnal cycle of winds at $10 \mathrm{~m}$ and precipitation during DJF of El Niño years from the control run, calculated by subtracting the climatological diurnal cycle from the composite diurnal cycle during El Niño years (the daily means have also been subtracted to highlight the diurnal cycle). During the morning hours (0100-1300 LT, where LT denotes the local standard time at Jakarta), the anomalous winds exhibit the character of land breezes diverging from Java Island toward the seas. During the afternoon and evening (1300-0100 LT), the anomalous winds and rainfall are sea breeze-like, converging from the northern and southern coasts to the island, especially toward mountainous areas near the southern coast (during the peak rainy time during the afternoon and evening,

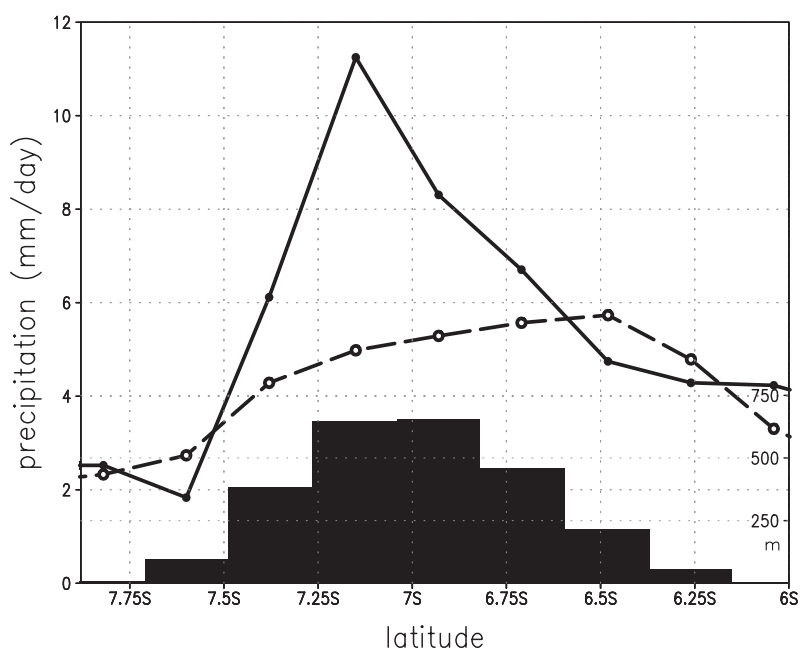

FIG. 4. Climatology of RegCM3 (1979-2002) precipitation (mm day ${ }^{-1}$, shaded) across Java Island along the meridional belt of $106.5^{\circ}-108.5^{\circ} \mathrm{E}$, averaged during DJF for the control run with mountains (solid) and the flat-island run (dashed). Black bars at the bottom illustrate terrain heights along the meridional belt. West Java latitudes range between $6.2^{\circ}$ and $7.7^{\circ} \mathrm{S}$ along the meridional belt.

1600-2200 LT). The anomalous diurnal cycles of winds and rainfall are in phase with the climatological diurnal cycle shown in Qian (2008). Hence the diurnal cycle is strengthened during DJF of El Niño years, with intensified convergence of valley winds toward the mountains that could enhance rainfall over the mountains. The modeling results indicate that the weaker monsoonal winds during DJF of El Niño years exert less interference on the local thermally driven diurnal cycle of winds and thus the strengthened land-sea breezes and mountain-valley winds change the fine-scale distribution of rainfall such that mountainous regions receive above normal rainfall.

To further examine the effect of mountains on the ENSO-related dipole pattern of rainfall anomalies over Java, Fig. 6 shows a north-south cross section of the composite of rainfall anomalies during El Niño years in western Java $\left(106.5^{\circ}-108.5^{\circ} \mathrm{E}\right.$, between the two dashed lines in Fig. 1a) in the control run and flat-island run. During SON (Fig. 6a), rainfall during El Niño years is less than the climatology; that is, rainfall anomalies are all negative from the northern to the southern coast, as large-scale atmosphere ascent is suppressed over the Maritime Continent during El Niño years because of the zonal displacement of the Walker circulation. The negative anomalies during SON of El Niño years are statistically significant above $90 \%$ level of the two-tailed Student's $t$ test. The magnitude of the rainfall anomalies is particularly large near the mountain ridge between $7^{\circ}$ and $7.5^{\circ} \mathrm{S}$. The negative anomalies are of the same sign as 

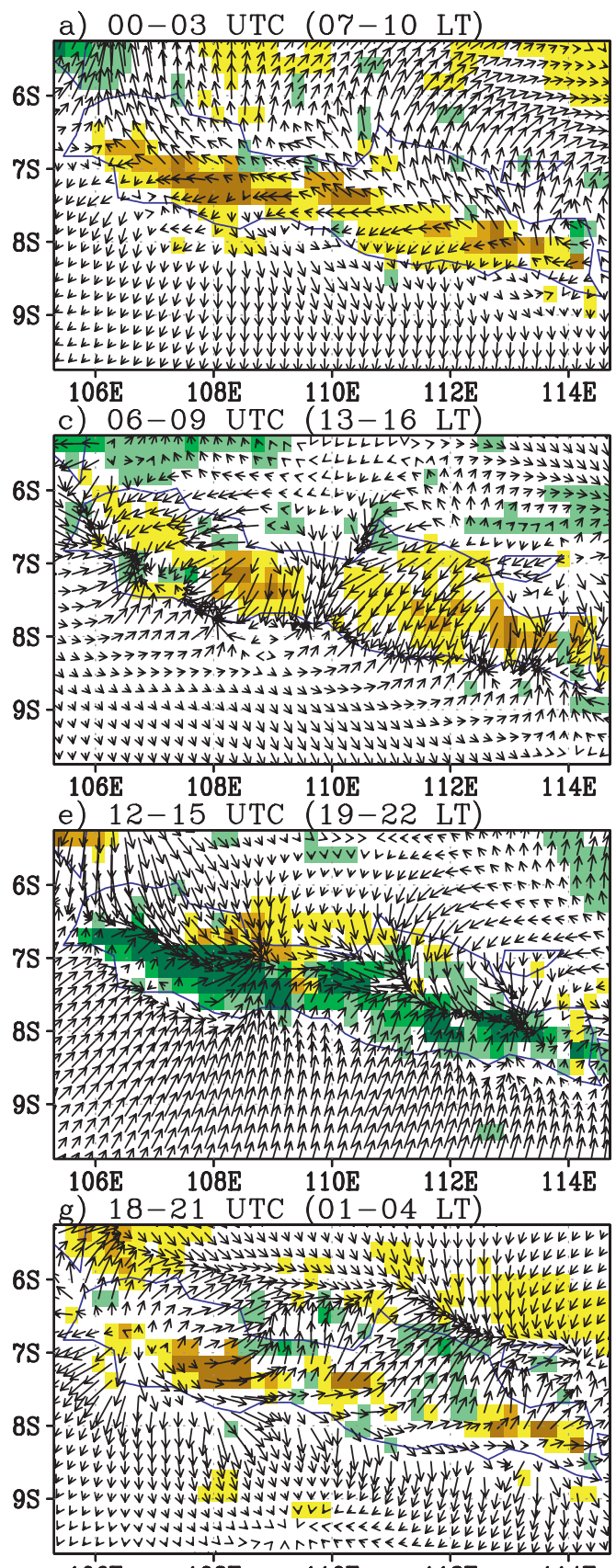

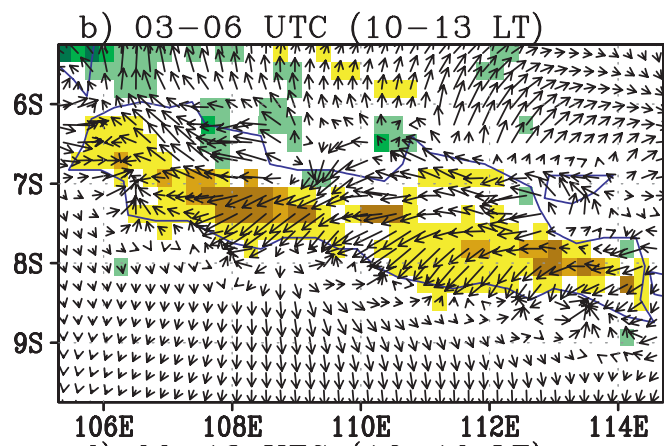

d) $09-12$ UTC $(16-19$ LT)

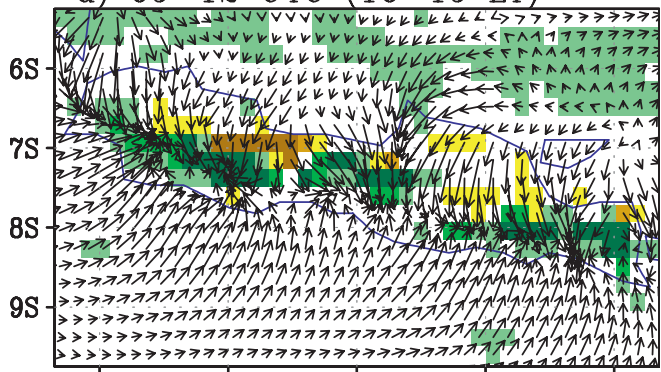

$106 \mathrm{E} \quad 108 \mathrm{E} \quad 110 \mathrm{E} \quad 112 \mathrm{E} \quad 114 \mathrm{E}$

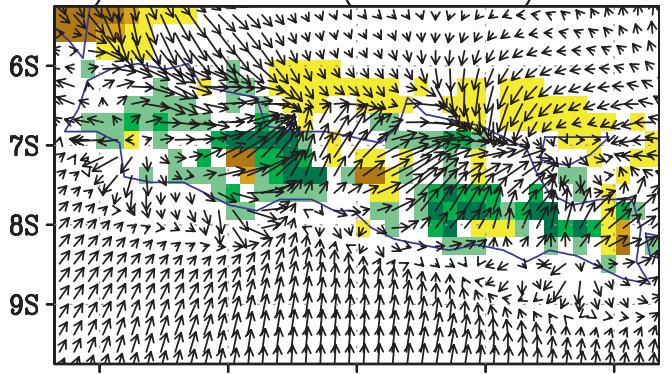

$\begin{array}{lllll}106 \mathrm{E} & 108 \mathrm{E} & 110 \mathrm{E} & 112 \mathrm{E} & 114 \mathrm{E}\end{array}$
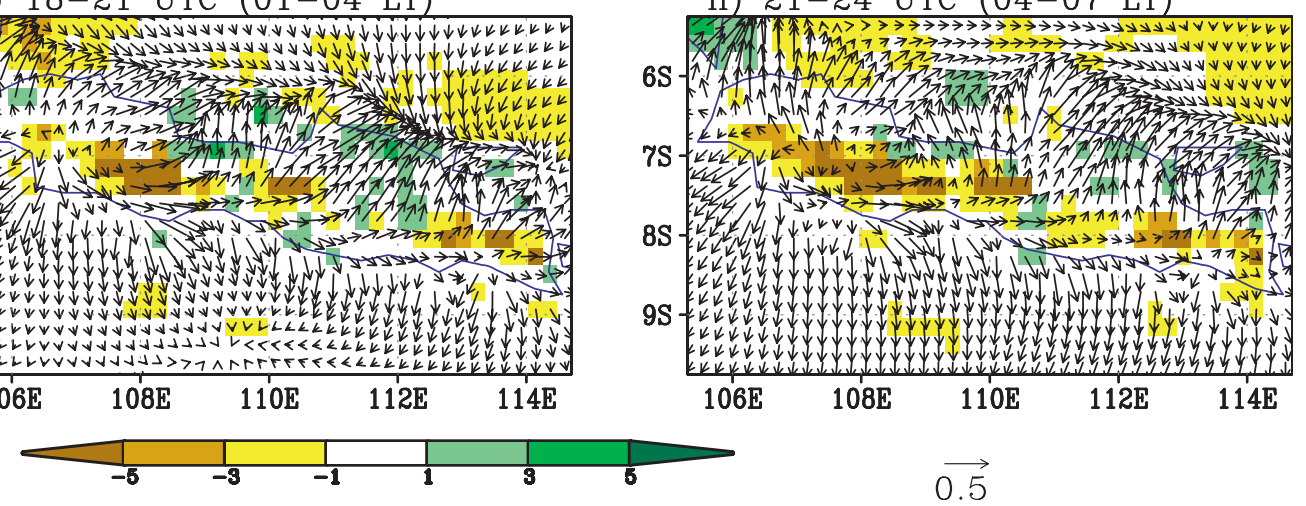

FIG. 5. The El Niño minus climatology composite of diurnal cycle of the NNRP-driving RegCM3 simulated precipitation ( $\mathrm{mm} \mathrm{day}^{-1}$, shaded), and winds $\left(\mathrm{m} \mathrm{s}^{-1}\right.$, vector) at $10 \mathrm{~m}$ during DJF. Daily means are subtracted to highlight the diurnal cycle. The El Niño years used for the composite are 1982/83, 86/87, 87/88, 91/92, 94/95, and 97/98.

those in the surrounding seas and most of Indonesia, consistent with the large-scale anomalous descent that suppresses rainfall (as indicated by Fig. 2b). The strengthened southeasterly monsoonal winds during SON of El Niño years would tend to disrupt the local thermally driven diurnal cycle of winds and thus to reduce their impact on rainfall. After the onset of wet season, with the reversal of background monsoonal winds (see Figs. 2c,d and $3 \mathrm{~b}, \mathrm{~d}$ ), the reduced monsoonal wind speed during DJF of El Niño years causes less interruption to the local 


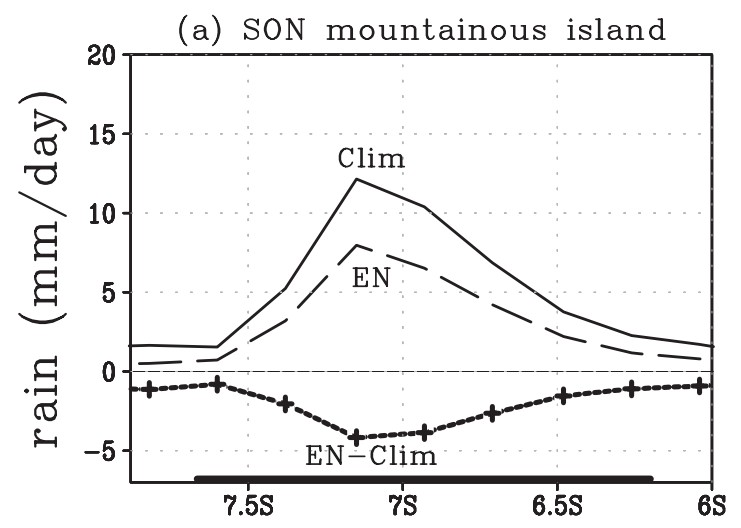

(b) DJF mountainous island

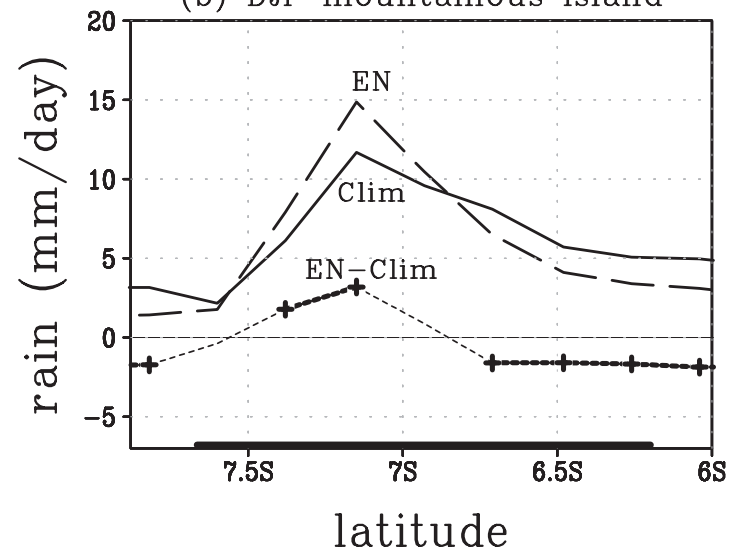

(c) SON flat island

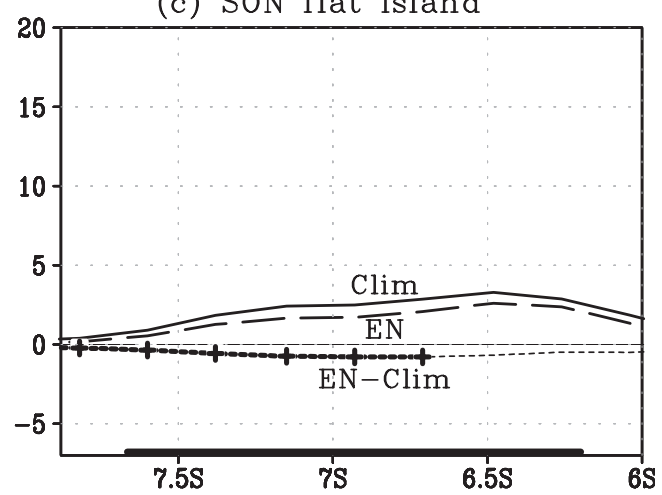

(d) DJF flat island

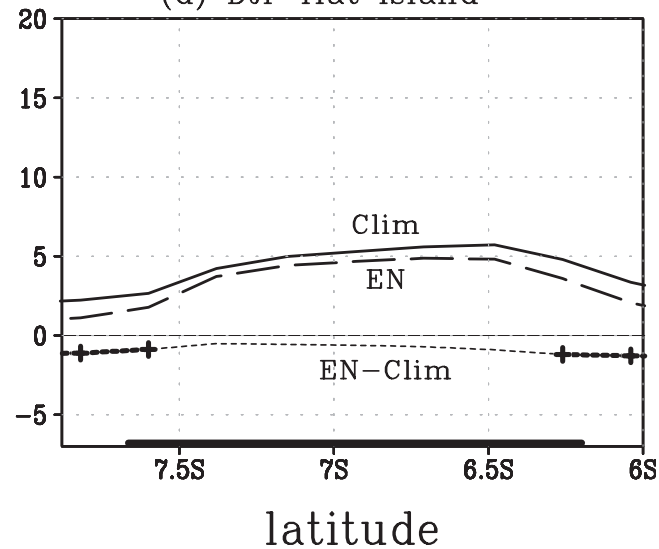

FIG. 6. The north-south cross section of the RegCM3 simulated seasonal precipitation ( $\mathrm{mm} \mathrm{day}^{-1}$ ): climatology (solid), El Niño-year composite (long dashed), and El Niño minus climatology (short dashed, where the differences statistically significant above $90 \%$ level of confidence using the Student's $t$ test are shown by thick dashed lines and crosses), along the meridional belt $\left(106.5^{\circ}-108.5^{\circ} \mathrm{E}\right)$ in western Java (the extend of the island, $6.2^{\circ}-7.7^{\circ} \mathrm{S}$, is illustrated by a thick line at the bottom of each panel) for (a),(c) SON and (b),(d) DJF in the (a),(b) mountainous control run and (c),(d) flat-island run. The El Niño years in the simulation period used in the composite calculation are 1982/83, 86/87, 87/88, 91/92, 94/95, and 97/98.

diurnal cycle of winds. In this case, rainfall anomalies are positive over the southern half of western Java (over the mountains) but negative over the northern half (coastal plain), indicating that the strengthened valley breezes converge over the mountain top to produce above normal rainfall. The rainfall anomalies in Fig. 6b is statistically significant (by the $t$ test) over the top and the southern slope of the central mountain range, and over the northern plain, in the cross section in West Java; but the rainfall anomalies are statistically insignificant over the northern slope of the mountain range, probably because of the relatively large inherent internal variability of rainfall over here during the peak of the wet season.

The cross section of the rainfall anomalies in West Java in the La Niña-year composite does not show a statistically significant dipolar pattern (not shown). This result is consistent with previous studies suggesting that the impact of La Niña is usually less significant than that of El Niño (Hoerling et al. 1997; Kumar and Hoerling 1998).
To demonstrate that the dipole pattern is indeed the result of mountain effects, we compare the control run with a regional model simulation in which the mountains are totally removed and replaced by a flat plain. Figures $6 \mathrm{c}$ and $6 \mathrm{~d}$ are results of the flat-island run during SON and DJF, respectively, in western Java from the south to the north along the cross section of the meridional belt of $106.5^{\circ}-108.5^{\circ} \mathrm{E}$ (Fig. 1a). During both seasons, the northsouth distribution of rainfall is quite even, and the rainfall anomalies during El Niño years are all slightly negative across the island. The rainfall anomalies are statistically significant in the middle and southern parts of the meridional belt in western Java during SON (Fig. 6c) but only significant over the Indian Ocean and Java Sea during DJF (Fig. 6d). The comparison of the control run and flatisland run seems to indicate that the north-south contrast of rainfall anomalies during El Niño years is probably caused by the interaction of large-scale monsoonal winds (associated with ENSO) and the diurnal cycle of winds 

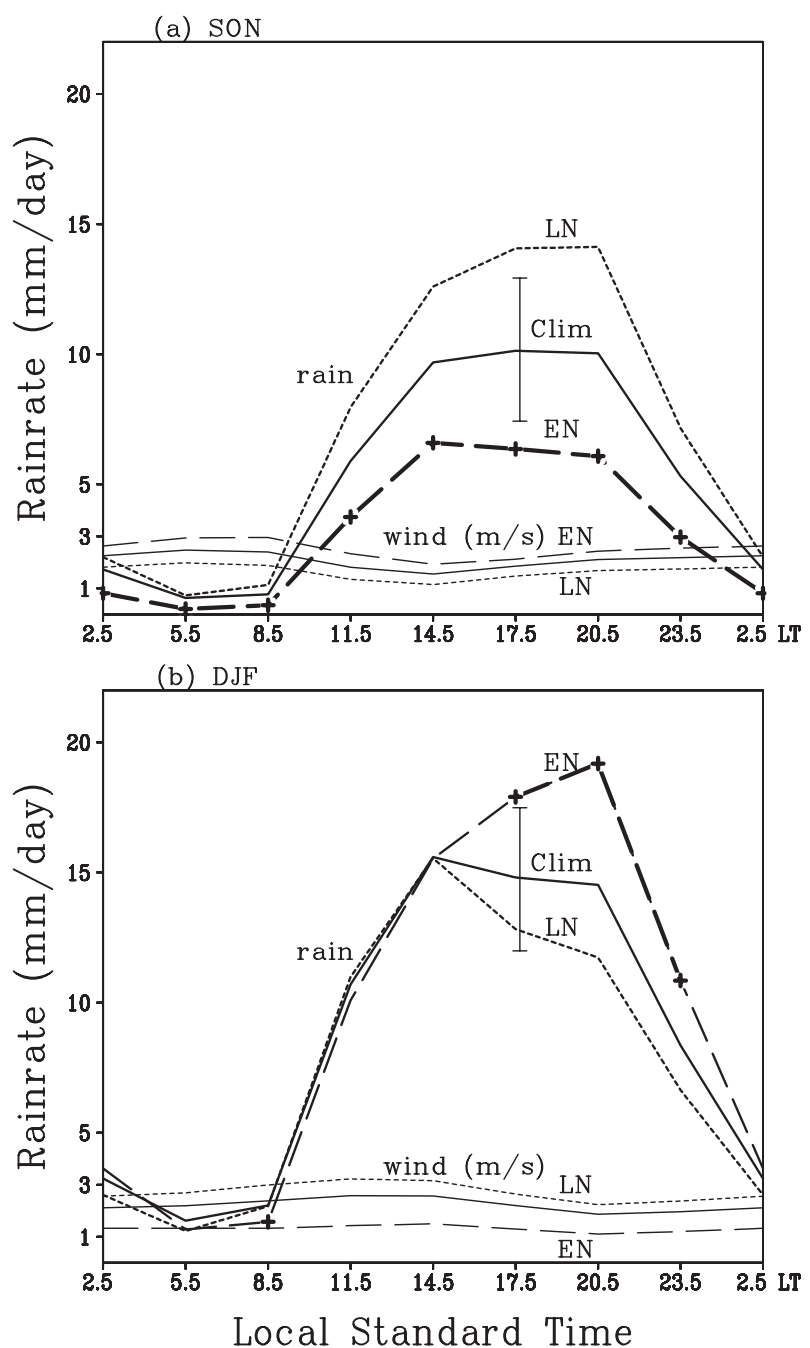

FIG. 7. Diurnal cycle of RegCM3 simulated rainfall (mm day ${ }^{-1}$, thick curves) and wind speed ( $\mathrm{m} \mathrm{s}^{-1}$, thin curves) over the whole area of Java Island during (a) SON and (b) DJF for climatology (solid), El Niño-year composite (long dashed), and La Niña-year composite (short dashed). Rainfall differences between ENSO years and climatology that are statistically significant above the $90 \%$ level of confidence using the Student's $t$ test are shown by thick lines and crosses. The range of the interannual variability of seasonal mean rainfall is illustrated by a vertical line with 1 std dev above and below the climate curve in each panel. Wind speeds $\left(\mathrm{m} \mathrm{s}^{-1}\right)$ at $10 \mathrm{~m}$ are plotted with the same scale. "LT" denotes the local standard time at Jakarta, Indonesia.

associated with the asymmetric topography over Java (i.e., the proximity of the mountains to the southern coast).

After checking the north-south cross section of rainfall in Fig. 6, we then examine the ENSO impact on the diurnal cycle of rainfall over the Java Island as a whole. Figure 7 shows the diurnal cycle (3-hourly bin) of the RegCM3 simulated precipitation and $10-\mathrm{m}$ wind speed averaged over all the areas of Java Island during SON
(Fig. 7a) and DJF (Fig. 7b) for the 22-yr climatology, and the composite of El Niño years and La Niña years, respectively. The range of the interannual variability of seasonal mean rainfall is roughly represented by a vertical line with a standard deviation above and below the climate curve in each panel. The rain rate is large during the afternoon hours and small during the morning hours. During SON (Fig. 7a), the 3-hourly rain rate is always smaller (larger) than the climatology throughout the day during El Niño (La Niña) years, especially during the afternoon. The diurnal cycle is thus weaker than normal during SON of El Niño years in which the anomalous winds (southeasterly) are of the same direction as the climatological winds (southeasterly) and thus mean wind speed is larger than that during normal years. The rainfall anomalies in the El Niño-year composite are statistically significant by the $t$ test. The La Niña-year composite anomalies are similar in magnitude to the ones of El Niño-year composite but are statistically not significant because of the larger rainfall variability over Java between the La Niña events. The climatological monsoonal winds during DJF are northwesterly, opposite to that of SON. Therefore during DJF (Fig. 7b), the mean wind speed is smaller (larger) than normal during El Niño (La Niña) years; hence, the diurnal cycle is stronger (weaker) than normal during El Niño (La Niña) years. In terms of the diurnal cycle of rain rate, the differences between the El Niño year and climate are significant during the peak rainy hours of the afternoon and evening (1600-0100 LT). Thus, the diurnal cycle is always stronger when large-scale monsoonal winds are weaker, during both SON and DJF.

\section{Relationships with daily weather types}

In this section we make use of the daily weather types (WTs) constructed by MRQ to investigate the changes in the diurnal cycle during ENSO events in detail. This method also enables us to make use of the 3-hourly highresolution CMORPH satellite estimates of rainfall to indirectly analyze the ENSO impact on the diurnal cycle of rainfall, which is otherwise impossible because of the relatively short record of the CMORPH data (starting from 7 December 2002).

MRQ used a $K$-means cluster analysis similar to that of Diday and Simons (1976) and Michelangeli et al. (1995) to classify weather regimes based on the unfiltered NNRP daily 850-hPa circulation field over the Maritime Continent region. Daily winds are standardized to zero mean and unit variance using the long-term AugustFebruary climatology and then prefiltered by the empirical orthogonal function analysis retaining the nine leading principal components, accounting for $75 \%$ of the 
total variance. Initially a prescribed number $k$ of clusters is specified and daily observations are agglomerated around centroids chosen from random seeds. Iterative clustering calculations are then carried out to minimize the sum, over all clusters, of the within-cluster spread, to finally reach the clusters that localize relatively high concentrations in data distribution in the atmospheric phase space. The multiyear daily time sequence of weather types describes a systematic monsoonal evolution, as well as the variability at seasonal and interannual time scales.

Five daily weather types (WT1-WT5) were identified by MRQ from the $K$-means cluster analysis during August-February over the Maritime Continent region, over the period 1979-2007, representing daily weather regimes during the premonsoon and wet season. These results are zoomed over an area around Java using composites in Fig. 8 in terms of 850-hPa winds (1979-2007), as well as the CMORPH rainfall averaged over all days for each WT during the available data period (2003-07). Both variables are plotted without the mean subtracted. The two relatively dry weather types over Java, WT1 and WT2, are characterized by southeasterly winds in the lower atmosphere over Java; these correspond to the premonsoon and transition phases of the seasonal evolution. The three rainy weather types, WT3, WT4, and WT5, have westerly winds over Java, corresponding to wet season winds, with much more rainfall over Java. Because wind speeds across monsoonal Indonesia south of the equator are small in WT4, it was referred to as the quiescent monsoon by MRQ. Note that although rainfall over the region surrounding Java is small in WT4 compared to WT3 and WT5, the rainfall over Java Island itself is appreciable. This is consistent with our previous analysis that local land-sea breezes are more prominent when the background monsoon is weak. In WT3 and WT5, strong westerly winds and relatively heavy rainfall cover most of the Indonesian region, but rainfall over Java Island is smaller than that in WT4.

Figure 9 shows the frequency of the five weather types averaged during all years, and during El Niño and La Niña years, during the premonsoon (SON; Fig. 9a) and wet monsoon (DJF; Fig. 9b), respectively. The sum of the frequencies of the five WTs for each season equals to $100 \%$; for example, the sum of blank bars in Fig. 9a is $100 \%$. The climatological seasonal evolution of WTs is such that WT1, WT2, and WT3 dominate during SON and then WT3, WT4, and WT5 prevail during DJF (see MRQ). The impact of ENSO on WT frequency is clearly marked during both seasons. During SON of El Niño events, the dry southeasterly WT2 becomes more frequent relative to the less frequent wet westerly weather type WT3, whereas during DJF the quiescent WT4
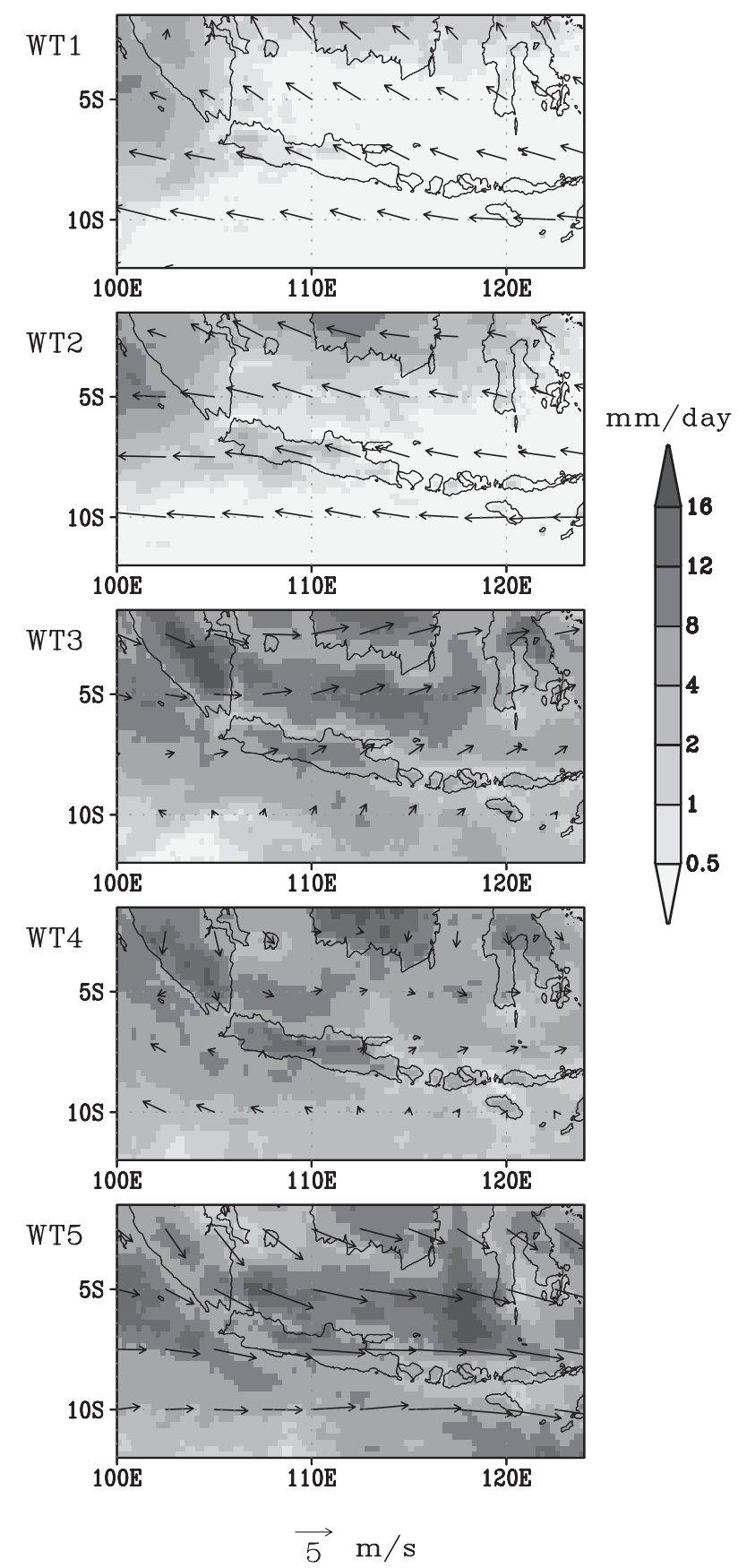

FIG. 8. Composites of CMORPH (2003-07) precipitation for WT1-WT5 (mm day ${ }^{-1}$, shaded) and NNRP reanalysis winds at $850 \mathrm{hPa}\left(\mathrm{m} \mathrm{s}^{-1}\right)$.

becomes much more prevalent at the expense of the strong westerly WT3 and WT5, as discussed in MRQ.

Next we analyze the diurnal cycles of rainfall in these five weather types to elucidate the role of ENSO in modulating the local rainfall distribution. The satelliteestimated precipitation of CMORPH data (December 

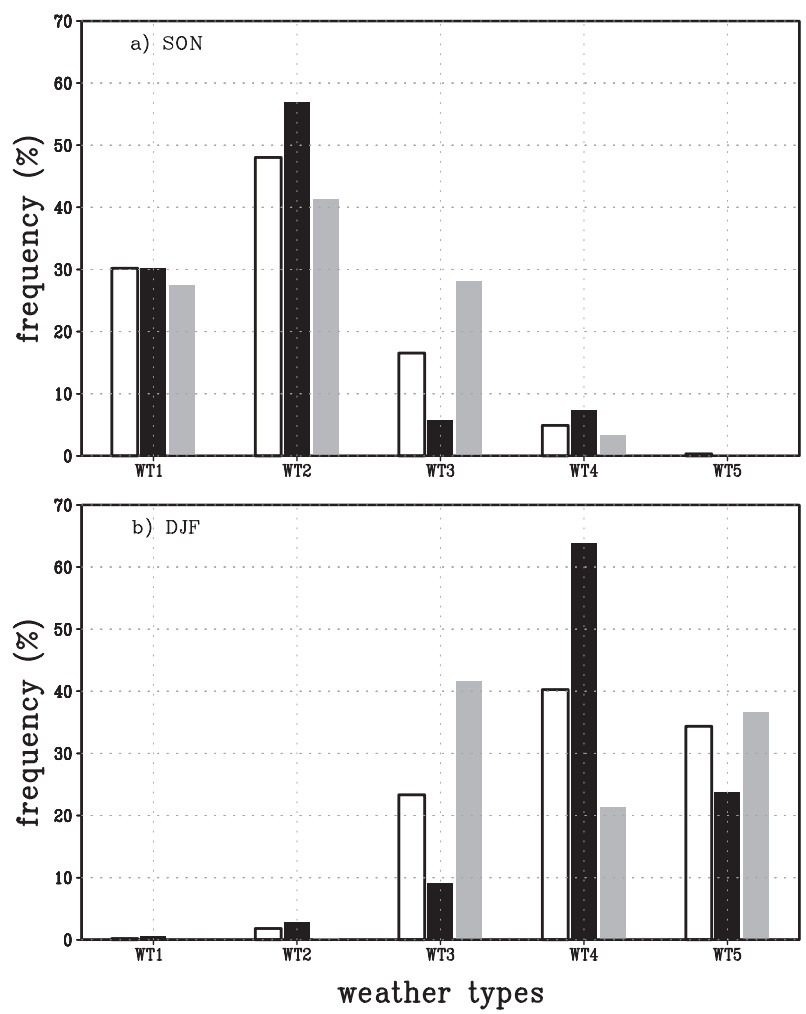

FIG. 9. Frequencies of WT1-WT5 during all years (white), El Niño years (black), and La Niña years (gray) during (a) SON and (b) DJF.

2002-present) is too short for ENSO composite analysis, but there are many days of different weather types for a composite analysis based on the weather types. Figure 10a shows the diurnal cycle of CMORPH rainfall for the five WTs averaged over the whole area of Java Island. The rain rate and the diurnal cycle are much smaller in the dry weather types (WT1 and WT2) than the wet ones (WT3-WT5). Note that the diurnal cycle of rainfall over Java Island is strongest for WT4, the quiescent monsoon type. Whereas the regional-scale rainfall over Indonesia as a whole is largest in the strong monsoon types WT3 and WT5 (Fig. 8), the quiescent WT4 produces the most rainfall over Java Island (Fig. 10a). Figure $10 \mathrm{~b}$ shows the diurnal cycle of the RegCM3simulated rainfall for the five WTs, in which WT4 also has a slightly stronger diurnal cycle than WT3 and WT5, consistent with the satellite data shown in Fig. 10a. However, the differences in simulated diurnal cycles between the WTs are much smaller than in the CMORPH when averaged over the whole of Java. Also note that the simulated diurnal cycle shows the early timing with somewhat flat peaks, probably due to the discrepancies in the cumulus scheme such as the insufficient representation of the entrainment/detrainment rate of clouds (Del Genio and $\mathrm{Wu} 2010)$.
As discussed earlier, the diurnal cycle over the mountains should be stronger than that over the plains because of the combined effect of in-phase land-sea and mountain-valley breezes. Figures 10c and 10d show the diurnal cycle of rainfall over the mountainous regions over Java (those areas with elevations higher than $250 \mathrm{~m}$ ). Indeed, the diurnal cycles over the mountains are stronger than the corresponding ones averaged over the whole island (Figs. 10a,b), particularly in the regional model. It is also apparent that more rainfall is received over the mountainous regions during quiescent large-scale weather conditions (WT4) than during the strong monsoon weather types WT3 and WT5.

During DJF of El Niño years, the northwesterly monsoon is weaker than normal, and the quiescent monsoon WT4 is the dominant weather type (Fig. 9b, with over $60 \%$ of frequency of occurrence by this weather type alone during the wet season), in which the intensified diurnal cycle of winds converges more moisture toward the mountainous region and produces more abundant rainfall there (Figs. 10c,d). Thus, we attribute the increase in rainfall over mountains at the expense of the plains during the wet season of El Niño years to the increased frequency of large-scale quiescent winds (WT4) that promote the diurnal cycle.

\section{Discussion of multiscale physical processes}

A new source of spatiotemporal variability of ENSOinduced rainfall anomalies over Java is identified, associated with multiscale processes of ENSO, the monsoon winds, subseasonal weather types, and local-scale diurnal sea/valley-breeze circulations. During the premonsoon and transition season SON, large-scale vertical motion associated with the Walker circulation and the localscale diurnal cycle of winds work in concert either to enhance rainfall (during La Niña years) or suppress rainfall (during El Niño years) over the mountainous Java Island. For instance, during El Niño years, the large-scale sinking associated with the Walker circulation suppresses rainfall over the Maritime Continent, and meanwhile the strengthened southeasterly monsoonal winds act to weaken the sea-breeze and valley-breeze convergence that also reduce rainfall over Java Island, especially over the mountains. Therefore, during SON, the magnitude of rainfall anomalies is quite large during both El Niño and La Niña years, with largest deviation from the climatology reaching up to $5 \mathrm{~mm}$ day ${ }^{-1}$ during the afternoon hours.

Unlike during SON, the large-scale vertical motion and local diurnal cycle during the monsoon during DJF work against each other to affect rainfall over Java. During DJF of El Niño years, although the large-scale 

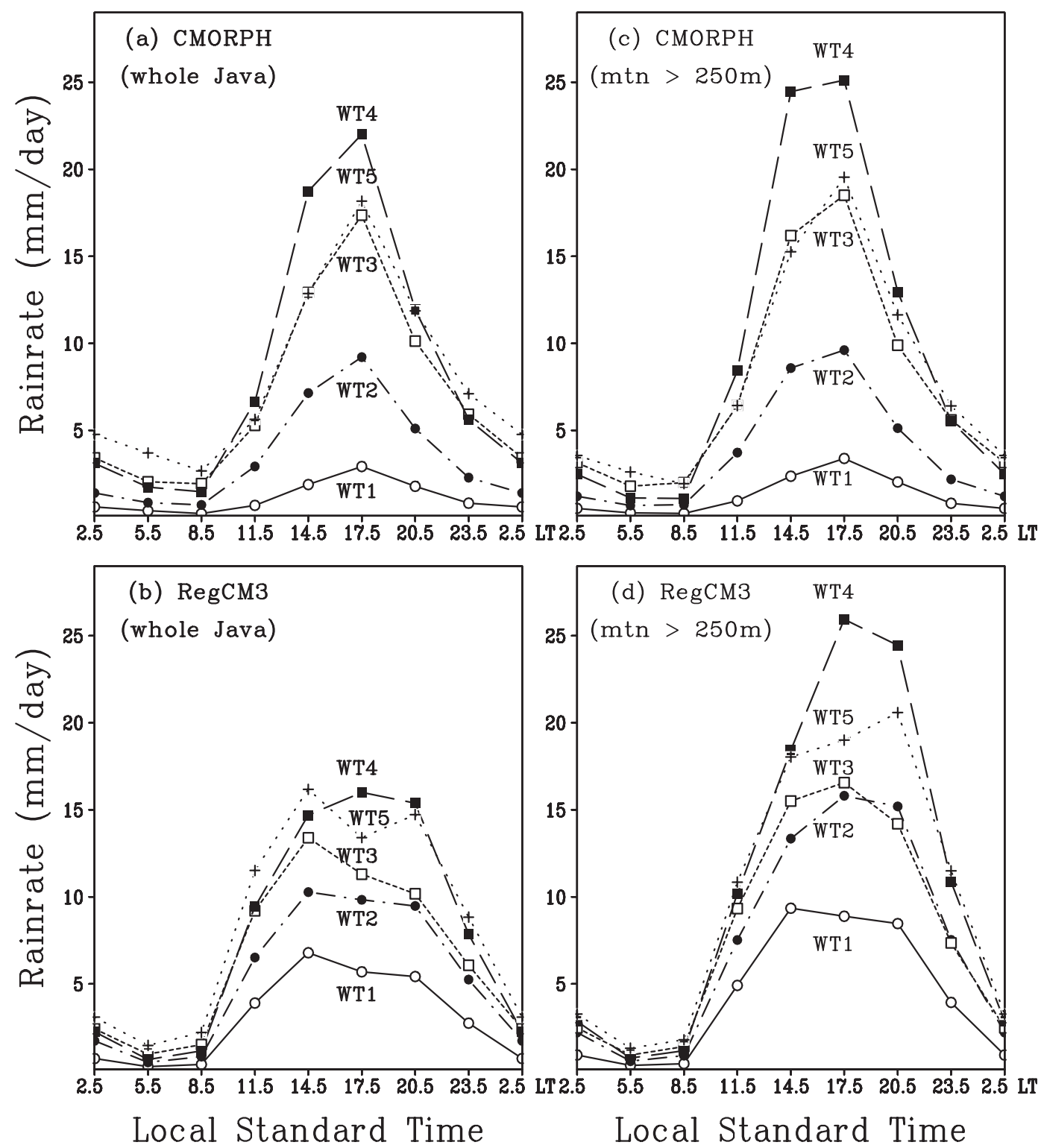

FIG. 10. Diurnal cycles of the CMORPH and RegCM3 rainfall $\left(\mathrm{mm} \mathrm{day}^{-1}\right.$ ) (a),(b) over the whole Java Island and (c),(d) over mountainous regions (terrain elevation higher than $250 \mathrm{~m}$ ) for WT1 (solid), WT2 (dot-dashed), WT3 (short dashed), WT4 (long dashed), and WT5 (dotted). "LT"' denotes the local standard time at Jakarta, Indonesia.

anomalous descent associated with the Walker circulation suppresses rainfall over Java, the strengthened seabreeze and valley-breeze convergence (due to the weaker than normal monsoon wind speed) enhances rainfall over Java. The results show that the local effect prevails over the large-scale effect, especially over the mountains. The maximum rain rate during DJF of El Niño years is larger than the climatology by about $5 \mathrm{~mm}$ day $^{-1}$ during the afternoon, and the positive anomalies are prolonged toward late evening. But during DJF of La Niña years, the diurnal cycle is only slightly weakened as compared to the climatology, indicating an asymmetry whereby the El Niño impacts are usually stronger than the La Niña impacts (Fig. 7).

Note that the ENSO impact on the averaged wet season rainfall over Java Island is somewhat opposite to the overall large-scale regional impact over the Maritime Continent shown in Fig. 2 d. The averaged rainfall is above (below) normal during El Niño (La Niña) years over Java Island during the afternoon hours. These ENSO-induced rainfall anomalies mostly result from the more prominent impact over the mountainous regions, namely the 
contrasting mountains/plains pattern of rainfall anomalies addressed by this paper. The rainfall is spatially redistributed, with more rainfall over the mountains and less rainfall over the plains and valleys, because of the intensified diurnal cycle of winds during El Niño years.

On subseasonal time scales, the weather typing analysis reveals that the major difference caused by ENSO during SON is the difference of frequencies between the dry and wet weather types, in that the fewer (greater) occurrences of the wet WT3 during SON of El Niño (La Niña) years causes negative (positive) rainfall anomalies over the whole Java Island during SON. In DJF, however, the ENSO impacts are the difference of frequencies between the three wet weather types. The most prominent feature is that the quiescent weak monsoon WT4 strongly prevails during El Niño years and exerts less influence on the thermally driven local diurnal cycle of land-sea breezes and mountain-valley winds, which converge to the mountainous regions, which are near the southern coast over western and eastern Java but near the middle in central Java, forming the heterogeneous pattern of rainfall anomalies-wet mountains versus dry plains and valleys-during El Niño years.

The northern coast and the valley regions over Java (where most people live) share the same sign of rainfall anomalies as most areas of Indonesia during El Niño years, consistent with the large-scale descending and stabilizing effect of the Walker circulation. This is probably why El Niño is generally perceived to cause below-normal rainfall over Java. However, the rainfall over Java Island as a whole does not necessarily decrease (in fact, it even slightly increases) during the wet season of El Niño years, as shown by the station rainfall, CMORPH satellite data, and modeling results (including more frequent WT4s, which produce more rainfall over mountains of Java Island). The smaller amount of rainfall over the plains and valleys is compensated by the excessive rainfall garnered over the mountains.

It should be noted that the above phenomenon of heterogeneous precipitation anomalies revealed by the composite analysis of RCM and station and satellite data is a general or canonical feature of El Niño's impact over Java. However, every El Niño event is somewhat different, according to the historical record. Therefore, whether the contrasting pattern of seasonal rainfall anomalies is realized during each El Niño event depends on the specific SST structure of that event. Also, we used an RCM with a grid size of $25 \mathrm{~km}$, so subgridscale forcings (such as small-scale hills and curved coastlines, which may cause further complexity) are still not fully resolved in the model (as indicated by the differences between Figs. 1a and 1b). However, since the intensity of the diurnal cycle is inversely proportional to the ambient large-scale monsoonal wind speed, it is perceivable that even at smaller spatial scales $(<25 \mathrm{~km})$, this variability of diurnal land-sea and mountain-valley winds will generally make flat places drier and high mountain areas wetter during the wet season of El Niño years, and vice versa during La Niña years. The above argument may also be valid for other islands with similar climate and topography, such as Sumatra, Sulawesi, and Timor, which warrants further investigation.

The dipolar pattern of rainfall anomalies over Java is probably not caused by the local SST anomalies over the adjacent coastal seas, as indicated by some previous studies as discussed below. In an observational study, Susanto et al. (2001) found an extended upwelling (with cooling of coastal SSTs) along the southern Java-Sumatra coasts during El Niño years. This local cooling effect is also supported by satellite-observed evidence of increased concentration of chlorophyll $a$ (which corresponds to upwelling cold waters) along the southern Java coast during the 1997/98 El Niño event during both the SON and DJF season, as can be seen in Fig. 4 of Susanto and Marra (2005). This cooling of SSTs along the southern coastal waters of Java should cause reduction (rather than increase) of rainfall over southern Java. Therefore, results from these studies seem to suggest that the coastal SST variability is unlikely to be the cause for the increased rainfall in the southern coastal lands over Java (thus the dipolar pattern discussed in this paper) during El Niño years.

The seasonally dependent mechanism for ENSOinduced rainfall anomalies over Java put forward in this paper may also be compared to other previous hypotheses for the decrease in spatial coherence (and seasonal predictability) from SON to DJF from the perspective of ENSO-monsoon interactions. Hendon (2003) hypothesized that El Niño rainfall anomalies lose coherence after monsoon onset because (large-scale) ENSO-induced wind speed anomalies decrease sharply when the seasonal winds reverse, progressing from a reinforcing to a canceling of the easterly anomalies and (seasonally dependent) mean field. In Hendon (2003)'s argument, the sharp drop in wind speed during El Niño reduces evaporation, allowing negative SST anomalies around Indonesia to warm, thus offsetting large-scale anomalous subsidence impact of El Niño over Indonesia. Giannini et al. (2007) argued that the tropical ocean-atmosphere equilibrates to ENSO and ENSO itself begins to decay, its direct influence diminishes, and regional features associated with the delayed response to ENSO become more prominent. In the current study, we demonstrate that the diurnal cycle is essential for the ENSO and monsoon influences on the local finescale rainfall distribution over Java. 


\section{Conclusions}

The interannual rainfall variability over Java has been analyzed using observation and regional climate modeling experiments. The mountain-plain dipolar pattern of rainfall anomalies associated with ENSO is revealed in both modeling and station data and its mechanism is analyzed from the perspective of multiscale physical processes: the Pacific Ocean basin-scale interannual variability of ENSO modulates the monsoon intensity over Indonesia, and the monsoon intensity affects the diurnal cycle of land-sea breezes over the Java Island and the mountain-valley winds within the island. The key is the inverse relationship between the intensity of the monsoonal wind speed and the amplitude of the diurnal cycle. The weakened northwesterly monsoon (by the more frequent occurrence of the daily quiescent weather regime) during the DJF of warm ENSO years causes the strengthened land-sea and mountain-valley breezes, which helps to retain negative rainfall anomalies over the coastal plains but acts to enhance low-level moisture convergence toward the central mountain range and produce more rainfall over the mountains. This is found to be the mechanism for the wetter mountains versus drier plains dipolar pattern of rainfall anomalies during the peak rainy season over Java Island associated with El Niño.

Acknowledgments. We wish to thank Filippo Giorgi, Xunqiang Bi, and other members in the Abdus Salam ICTP, the developers of RegCM3. We also thank Alessandra Giannini for discussions. We are grateful for the constructive comments of three anonymous reviewers and the editor that helped to improve the paper greatly. The IRI represents a cooperative agreement between the U.S. National Oceanic and Atmospheric Administration (NOAA) Office of Global Programs and Columbia University. The paper is funded through a corporative agreement with NOAA, Grant NA05OAR4311004. The views expressed herein are those of the authors and do not necessarily reflect the views of NOAA or any of its subagencies.

\section{REFERENCES}

Aldrian, E., and R. D. Susanto, 2003: Identification of three dominant rainfall regions within Indonesia and their relationship to sea surface temperature. Int. J. Climatol., 23, 1435-1452.

Bjerknes, J., 1969: Atmospheric teleconnections from the equatorial Pacific. Mon. Wea. Rev., 97, 163-172.

Cane, M. A., and S. E. Zebiak, 1985: A theory for El Niño and Southern Oscillation. Science, 228, 1085-1087.

Chang, C. P., Z. Wang, J. McBride, and C.-H. Liu, 2005: Annual cycle of Southeast Asia-Maritime Continent rainfall and asymmetric monsoon transition. J. Climate, 18, 287-301.
Del Genio, A. D., and J. Wu, 2010: The role of entrainment in the diurnal cycle of continental convection. J. Climate, 23, 2722 2738.

Diday, E., and J. C. Simons, 1976: Clustering analysis. Digital Pattern Recognition, Communication and Cybernetics, Vol. 10, K. S. Fu, Ed., Springer, 47-94.

Erasmi, S., P. Propastin, M. Kappas, and O. Panferov, 2009: Spatial patterns of NDVI variation over Indonesia and their relationship to ENSO warm events during the period 1982-2006. J. Climate, 22, 6612-6623.

Giannini, A., A. W. Robertson, and J.-H. Qian, 2007: A role for tropical tropospheric temperature adjustment to El NiñoSouthern Oscillation in the seasonality of monsoonal Indonesia precipitation predictability. J. Geophys. Res., 112, D16110, doi:10.1029/2007JD008519.

Giorgi, F., J. S. Pal, X. Bi, L. Sloan, N. Elguindi, and F. Solmon, 2006: The RegCNET network. Theor. Appl. Climatol., 86, $1-4$.

Hamada, J. I., M. D. Yamanaka, J. Matsumoto, S. Fukao, P. A. Winarso, and T. Sribimawati, 2002: Spatial and temporal variations of the rainy season over Indonesia and their link to ENSO. J. Meteor. Soc. Japan, 80, 285-310.

Haylock, M., and J. McBride, 2001: Spatial coherence and predictability of Indonesian wet season rainfall. J. Climate, 14, 3882-3887.

Hendon, H. H., 2003: Indonesian rainfall variability: Impacts of ENSO and local air-sea interaction. J. Climate, 16, 17751790.

Hoerling, M. P., A. Kumar, and M. Zhong, 1997: El Niño, La Niña, and the nonlinearity of their teleconnections. J. Climate, 10, 1969-1986.

Hung, C.-W., X. Liu, and M. Yanai, 2004: Symmetry and asymmetry of the Asian and Australian summer monsoons. J. Climate, 17, 2413-2426.

Janowiak, J. E., V. E. Kousky, and R. J. Joyce, 2005: Diurnal cycle of precipitation determined from the CMORPH high spatial and temporal resolution global precipitation analyses. J. Geophys. Res., 110, D23105, doi:10.1029/2005JD006156.

Juneng, L., and F. T. Tangang, 2005: Evolution of ENSO-related rainfall anomalies in Southeast Asia region and its relationship with atmosphere-ocean variations in Indo-Pacific sector. Int. J. Climatol., 25, 337-350.

Kalnay, E., and Coauthors, 1996: The NCEP/NCAR 40-Year Reanalysis Project. Bull. Amer. Meteor. Soc., 77, 437-471.

Klein, S. A., B. J. Soden, and N.-C. Lau, 1999: Remote sea surface temperature variations during ENSO: Evidence for a tropical atmospheric bridge. J. Climate, 12, 917-932.

Kumar, A., and M. P. Hoerling, 1998: Annual cycle of PacificNorth America seasonal predictability associated with different phases of ENSO. J. Climate, 11, 3295-3308.

Li, C., and M. Yanai, 1996: The onset and interannual variability of the Asian summer monsoon in relation to land-sea thermal contrast. J. Climate, 9, 358-375.

McBride, J. L., M. R. Haylock, and N. Nicholls, 2003: Relationships between the Maritime Continent heat source and the El Niño-Southern Oscillation phenomena. J. Climate, 16, 2905-2914.

Michelangeli, P. A., R. Vautard, and B. Legras, 1995: Weather regimes: Recurrence and quasi-stationarity. J. Atmos. Sci., 52, 1237-1256.

Moron, V., A. W. Robertson, and R. Boer, 2009: Spatial coherence and seasonal predictability of monsoon onset over Indonesia. J. Climate, 22, 840-850. 
, - - and J.-H. Qian, 2010: Local versus regional-scale characteristics of monsoon onset and post-onset rainfall over Indonesia. Climate Dyn., 34, 281-299.

Pal, J. S., and Coauthors, 2007: Regional climate modeling for the developing world: The ICTP RegCM3 and RegCNET. Bull. Amer. Meteor. Soc., 88, 1395-1409.

Qian, J.-H., 2008: Why precipitation is mostly concentrated over islands in the Maritime Continent. J. Atmos. Sci., 65, 1428-1441.

Ramage, C. S., 1968: Role of a tropical "maritime continent" in the atmospheric circulation. Mon. Wea. Rev., 96, 365-370.

Ropelewski, C. F., and M. S. Halpert, 1987: Global and regional scale precipitation patterns associated with the El Niño/ Southern Oscillation. Mon. Wea. Rev., 115, 1606-1626.
Susanto, R. D., and J. Marra, 2005: Effect of 1997/98 El Niño on chlorophyll $a$ variability. Oceanography, 18, 124-127.

_ A. L. Gordon, and Q. Zheng, 2001: Upwelling along the coasts of Java and Sumatra and its relation to ENSO. Geophys. Res. Lett., 28, 1599-1602.

Wang, B., R. Wu, and X. Fu, 2000: Pacific-East Asia teleconnection: How does ENSO affect Asian climate? J. Climate, 13, 1517-1536.

Xie, P., and P. A. Arkin, 1996: Analyses of global monthly precipitation using gauge observations, satellite estimates, and numerical model predictions. J. Climate, 9, 840-858.

Zebiak, S. E., 1982: A simple atmospheric model of relevance to El Niño. J. Atmos. Sci., 39, 2017-2027. 